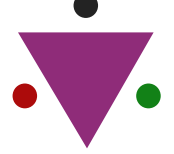

IJCRR

Section: Healthcare

Sci. Journal Impact

Factor: 6.1 (2018)

ICV: 90.90 (2018)

(c) (1) (9)

Copyright@IJCRR

\title{
Yogic Eye Exercises Followed by the Ergonomic Advice on Eye Fatigue in Children Attending Online Classes in COVID-19
}

\section{Mujahid K Sheikh', ${ }^{1}$ Rutuja Malavde ${ }^{2}$, Sachin Daigavane ${ }^{3}$}

\author{
'Assistant Professor, Datta Meghe College of Physiotherapy Nagpur, India; ${ }^{2}$ Physiotherapist, Datta Meghe College of Physiotherapy

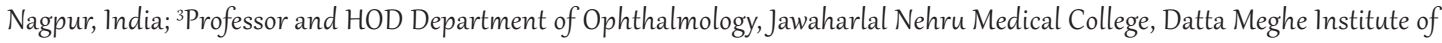 \\ Medical Sciences, Wardha, Maharashtra, India.
}

\section{ABSTRACT}

Background: Computer use by children especially school-aged children is growing rapidly. In these decades, due to the rising use of IT, they are using computers or laptops not only for education purpose but also, for playing online games for a prolonged period. Therefore, extensive viewing of the computer screen can lead to eye discomfort, fatigue, blurred vision and headaches, dry eyes and other symptoms of eyestrain. But nowadays, in this hazardous situation, it has been compulsive and essential for the children to get an education by attending online lectures at home environment.

Methodology: 44 school-aged children attending online classes in the age group 6 to 15 years were included. Eye fatigue was assessed through the 7-point Likert Scale before the exercise session. The participants were instructed to follow the eye exercises and ergonomic advice for 6 days per week (twice a day) as a 4 weeks protocol. After the exercise session, again eye fatigue was assessed through the 7-point Likert Scale. Later data were collected and analysis was done.

Results: A significant reduction was seen in eye fatigue with self- relaxing yogic eye exercises followed by the ergonomic advice in school-aged children attending online classes in COVID-19.

Conclusion: Eye fatigue was significantly reduced in the post-exercise session followed by the ergonomic advice as compared to the pre-exercise session in school-aged children attending online classes..

Key Words: Eye fatigue, Computer use, Children, Eye exercises, Ergonomic advice

\section{INTRODUCTION}

Eyes are the vital organs in every individual's daily lives. Except during sleep, a huge variety of visual information is recognized by us through eye both at work and at home. Most of the users of visual displays have reported forms of visual discomfort such as tired eyes, dry eyes, eye strain, eye irritation, poor visual acuity, burning sensations, redness, and double vision. ${ }^{1}$

Computer use by children especially school-aged children is growing rapidly. ${ }^{2}$ They are using computers for various purpose such as educational purpose, for leisure pursuits and communication, in both schools as well as the home environment. According to the research in the ergonomics of children computer use, there are potential effects of computer use on a child's health, satisfaction and productivity. ${ }^{3}$
Today in Western Societies, information technology plays a major role in children lives. ${ }^{4}$ Based on a systemic reviews established by Masshall, et. al (2006), it has been reported that children are likely to use IT such as television, computers and electronic games for $25 \%$ of their waking hours. Laptops, mobile phones, electronic games along with television, has now denoted to be essential by many families. ${ }^{5}$

Computer use in specific is a necessary or essential type of IT with children using desktop and laptop computers to play games, complete learning programs, write documents, work with pictures and music in multi-media programs, surf the internet and communicate by email and chat rooms. ${ }^{6}$ With the rising use of computers and the internet at both school as well as home, the number of children using computers and their daily exposures has markedly increased. ${ }^{4,7}$

Recent literature describes that children computers exposure is influenced by a variety of factors involving environmental

\section{Corresponding Author:}

Dr. Muzahid K Sheikh, Assistant Professor, Datta Meghe College of Physiotherapy, Nagpur, Maharashtra, India. Contact: 9623752755; Email: msmuzahid@gmail.com

ISSN: $2231-2196$ (Print)

Received: 18.06 .2020
ISSN: $0975-5241$ (Online)

Revised: 28.07 .2020
Accepted: 24.08 .2020
Published: 08.09.2020 
factors of access, location and socio-economic factors such as age, gender, psychological attributes and general activity participation. Nearly, all children in the communities use computers at school and most of them use computers at home. ${ }^{8}$ Many studies reported that boys are more likely to have a higher vulnerability to computers as compared to girls. ${ }^{9}$ In Chou and Tsai's (2007) study, children computer exposure was usually used for gaming activities only, which is used more by the boys than the girls. ${ }^{10}$

The result of children computer exposure has markedly been both positive as well as negative., ${ }^{71}$ Positive effects include increased socialization, ${ }^{10,12}$ improved learning and academic skills ${ }^{13}$ and improved fine motor and eye-hand co-ordination skills. ${ }^{14}$ Negative effects include poor psychological development such as aggressive behaviour, violence, addiction, depression, attention deficits, somatic well- being, ${ }^{15}$ poor physical development ${ }^{16}$ and general health issues such as sleep deprivation and reduced nutrition. ${ }^{17}$

In this context, eye fatigue is a common complaint due to computer usage for academic or recreational purposes or social networking. ${ }^{18}$ Generally, eye fatigue can be developed by factors including insufficient lighting, prolonged watching of visual displays, poor diet, eye muscle insufficiency due to prolonged hours of office work and academic studies, psychological and emotional tension and ageing. ${ }^{19}$ In a recent state, university students are readily exposed to accelerated environmental eye fatigue as a common as well as frequent users of computer screens. ${ }^{18}$

Previous studies have proposed that eye disorders are often related to functional defects in the ocular muscles aggravated by pain and tension resulting from computer work. ${ }^{19,} 20$ Hence, relaxation practices can help to relieve eye fatigue. ${ }^{21}$ Yoga practices correlate with physical as well as mental health benefits via down-regulation of the hypothalamicpituitary-adrenal axis and the sympathetic nervous system. ${ }^{22}$ Previous studies proposed that yoga exercises are associated with better self-rated relaxation. ${ }^{23}$ Also, according to a few studies it has been reported that the practice of eye yoga helps to relieve eye fatigue.

Hence, the purpose of this study was to assess the effects of self- relaxing yogic eye exercises along with ergonomic advice on eye fatigue in school-aged children attending online classes in COVID-19 phase.

\section{MATERIAL AND METHODOLOGY}

This study was done to find the effect of self-relaxing yogic eye exercises followed by the ergonomic advice on eye fatigue in school-aged children attending online classes in COVID-19. The study was carried out through a randomized sampling method using a lottery method in which 44 school- aged children participated. The purpose of the study was explained to the participants through an online session and consent was taken through an online form. 44 school-aged children were taken for the study. The inclusion criteria were the participants those who were willing to participate in the age group of between 6 to 15 years and those who were attending online classes in COVID-19. The exclusion criteria were the participants those who were not willing to participate, those having colour blindness and those who were using eye spectacles since from their childhood onwards. 7- point Likert Scale questionnaire was the major outcome measure to assess eye fatigue in children. Demographic information and eye fatigue scores were measured as pre-test data (i.e. before the exercise session) Eye fatigue scores were also measured as post-test data (i.e. after the exercise session). The participants were instructed to follow the eye exercises along with ergonomic advice for 6 days per week (twice a day) as a 4 weeks protocol. Eye fatigue was measured using a questionnaire known as the 7-point Likert Scale for evaluating ocular fatigue. This questionnaire consisted of 11 items: tired eyes, sore/aching eyes, irritated eyes, watery eyes, dry eyes, eyestrain, hot/burning eyes, blurred vision, difficulty focusing, double vision, and visual discomfort with the following responses: $0=$ none, $1=$ slight, $2=$ moderate, $3=$ severe. Yogic eye exercises were conducted for about one hour per session, twice a week for 4 weeks. They consisted of 8 steps: palming, blinking, sideways viewing, front and sideways viewing, rotational viewing, up and down viewing, preliminary nose-tip gazing, near and distant viewing etc. Each step was performed for 5 minutes per cycle. After the eye exercises, the participants practised the Shavasana for 20 minutes to relax their eyes. The importance and benefits of each exercise were explained as follows: relaxes and revitalize of the eye muscles, relaxes the tension of muscles strained by constant reading and close work, preventing and correcting squint, improves the coordination of medial and lateral muscles, restores balance in the muscles surrounding the eyes and improves the coordinated activity of both eyeballs, balances the upper and lower eyeball muscles, improves the accommodating and focusing power of the eye muscles, and increases the range of movements. Finally, the results were the key outcome to determine the effect of selfrelaxing yogic eye exercises followed by the ergonomic advice on eye fatigue in the subjects. Then, statistical analysis and interpretation were done for each candidate to find out the effect of self- relaxing yogic eye exercises followed by the ergonomic advice on eye fatigue in school-aged children attending online classes in COVID-19 phase.

Statistical analysis of the recorded data was done by using the software INSTAT App. The unpaired t-test was used to determine $\mathrm{p}$-value which differed from pre-data to postdata. 


\section{RESULTS}

\section{Interpretation}

In this present study, out of 44 children's 26 were males and 18 were females respectively.

And in this percentage Male- $59 \%$, Female- 41\% (Table 1)

Table 1: shows age, BMI and class-wise distribution

\begin{tabular}{|c|c|c|c|c|c|}
\hline Tests & Mean & $\begin{array}{l}\text { Standard } \\
\text { Deviation }\end{array}$ & $\begin{array}{c}\mathrm{T} \\
\text { Value }\end{array}$ & P Value & Interference \\
\hline AGE & 12.10 & 2.36 & 33.92 & $<0.0001$ & $\begin{array}{l}\text { Extremely } \\
\text { Significant }\end{array}$ \\
\hline BMI & 19.55 & $5 \cdot 35$ & 24.23 & $<0.0001$ & $\begin{array}{l}\text { Extremely } \\
\text { Significant }\end{array}$ \\
\hline CLASS & 7.09 & 2.38 & 19.76 & $<0.0001$ & $\begin{array}{l}\text { Extremely } \\
\text { Significant }\end{array}$ \\
\hline $\begin{array}{l}\text { Total } \\
\text { Hours of } \\
\text { Lectures }\end{array}$ & 4.45 & 2.14 & 13.80 & $<0.0001$ & $\begin{array}{l}\text { Extremely } \\
\text { Significant }\end{array}$ \\
\hline
\end{tabular}

Statistical analysis was done by using unpaired t-Test.
Participants mean age, BMI, class, total hours of lectures were 12.10 years, $19.55 \mathrm{~kg} / \mathrm{m} 2,7.09$ and 4.45 hours respectively. Statistical significance was set at $\mathrm{P}<0.0001$. After analyzing and comparing the data significant effect was found on eye fatigue by self- relaxing yogic eye exercises followed by ergonomic advice in school-aged children attending online classes in COVID-19.

The participants were instructed to follow the eye exercises and ergonomic advice for 6 days per week (twice a day) as a 4 weeks protocol. Eye fatigue scores were measured as pre-test data (i.e. before the exercise session) and also as post-test data (i.e. after the exercise session). The results which showed significant change are as follows: (Table-2)

Table 2: Comparison of Results Before and after the Exercise Session

\begin{tabular}{|c|c|c|c|c|c|c|c|c|c|}
\hline \multirow[t]{2}{*}{ Sr. No } & \multirow[t]{2}{*}{ Questions } & \multicolumn{2}{|c|}{ MEAN + SD } & \multicolumn{2}{|c|}{ t Value } & \multicolumn{2}{|c|}{ p Value } & \multicolumn{2}{|c|}{ INTERFERENCE } \\
\hline & & $\begin{array}{l}\text { PRE- } \\
\text { DATA }\end{array}$ & $\begin{array}{l}\text { POST- } \\
\text { DATA }\end{array}$ & $\begin{array}{l}\text { PRE- } \\
\text { DATA }\end{array}$ & $\begin{array}{l}\text { POST- } \\
\text { DATA }\end{array}$ & $\begin{array}{l}\text { PRE- } \\
\text { DATA }\end{array}$ & $\begin{array}{l}\text { POST- } \\
\text { DATA }\end{array}$ & PRE- DATA & POST- DATA \\
\hline 1 & Tired Eyes & $1.27+0.65$ & $0.11+0.32$ & 12.79 & 2.34 & $<0.0001$ & 0.0235 & $\begin{array}{l}\text { Extremely } \\
\text { Significant }\end{array}$ & Significant \\
\hline 2 & Sore/ aching Eyes & $\begin{array}{c}1.09+ \\
0.74\end{array}$ & $\begin{array}{c}0.04+ \\
0.21\end{array}$ & $9 \cdot 76$ & 1.43 & $<0.0001$ & 0.1597 & $\begin{array}{l}\text { Extremely } \\
\text { Significant }\end{array}$ & Significant \\
\hline 3 & Irritated Eyes & $\begin{array}{c}0.77+ \\
0.64\end{array}$ & $\begin{array}{c}0.04+ \\
0.21\end{array}$ & 7.98 & 1.43 & $<0.0001$ & 0.1597 & $\begin{array}{l}\text { Extremely } \\
\text { Significant }\end{array}$ & Significant \\
\hline 4 & Watery Eyes & $\begin{array}{c}0.86+ \\
0.76\end{array}$ & $0.13+0.34$ & 0.12 & 2.6 & $<0.0001$ & 0.0125 & $\begin{array}{l}\text { Extremely } \\
\text { Significant }\end{array}$ & Significant \\
\hline 5 & Dry Eyes & $\begin{array}{c}0.34+ \\
0.47\end{array}$ & $\begin{array}{c}0.02+ \\
0.15\end{array}$ & $4 \cdot 71$ & 1 & $<0.0001$ & 0.3229 & $\begin{array}{l}\text { Extremely } \\
\text { Significant }\end{array}$ & Significant \\
\hline 6 & Eye Strain & $1.18+0.78$ & $0.15+0.37$ & $9 \cdot 97$ & 2.85 & $<0.0001$ & 0.0066 & $\begin{array}{l}\text { Extremely } \\
\text { Significant }\end{array}$ & Significant \\
\hline 7 & $\begin{array}{l}\text { Hot/ burning } \\
\text { Eyes }\end{array}$ & $\begin{array}{c}0.63+ \\
0.65\end{array}$ & $0+0$ & 6.49 & & $<0.0001$ & & $\begin{array}{l}\text { Extremely } \\
\text { Significant }\end{array}$ & \\
\hline 8 & Blurred Vision & $\begin{array}{c}0.90+ \\
0.67\end{array}$ & $0.15+0.37$ & 8.92 & 2.85 & $<0.0001$ & 0.0066 & $\begin{array}{l}\text { Extremely } \\
\text { Significant }\end{array}$ & Significant \\
\hline 9 & $\begin{array}{l}\text { Difficulty in } \\
\text { focusing }\end{array}$ & $\begin{array}{c}1.09+ \\
0.77\end{array}$ & $\begin{array}{c}0.09+ \\
0.29\end{array}$ & $9 \cdot 37$ & 2.07 & $<0.0001$ & 0.04 & $\begin{array}{l}\text { Extremely } \\
\text { Significant }\end{array}$ & Significant \\
\hline 10 & Double Vision & $\begin{array}{c}0.29+ \\
0.63\end{array}$ & $\begin{array}{c}0.02+ \\
0.15\end{array}$ & 3.1 & 1 & 0.03 & 0.3229 & $\begin{array}{l}\text { Very Signifi- } \\
\text { cant }\end{array}$ & Significant \\
\hline 11 & $\begin{array}{l}\text { Visual Discom- } \\
\text { fort }\end{array}$ & $\begin{array}{c}0.72+ \\
0.78\end{array}$ & $\begin{array}{c}0.04+ \\
0.21\end{array}$ & 6.11 & 1.43 & $<0.0001$ & 0.1597 & $\begin{array}{l}\text { Extremely } \\
\text { Significant }\end{array}$ & Significant \\
\hline
\end{tabular}




\section{DISCUSSION}

The purpose of the present study was to find out the effect of self-relaxing yogic eye exercises followed by the ergonomic advice on eye fatigue in school-aged children attending online classes in COVID-19. A significant reduction was seen in eye fatigue with self- relaxing yogic eye exercises followed by the ergonomic advice in school-aged children attending online classes. This result confirms our null hypothesis by previous reports.

Eyes are the vital organs in every individual's daily lives. The main function of the eye muscles is the execution of eye movements. The muscles surrounding the eye, control many diverse eye movements. Although, these muscles are small and are not particularly strong, Exceptionally quick and accurate. They help the eye to perform many complex tasks, including tracking moveable objects, scanning objects and maintaining a steady image on the retina. Hence, fatigue in these muscles, makes it difficult to focus vision and can cause pain.

Computer use by children especially school-aged children is growing rapidly. They use computers, laptops or mobile phones not only for entertainment purpose but also for education purpose which leads to eye muscle fatigue. Hence, it is important to reduce eye fatigue and also to strengthen the eye muscles to work more efficiently and effectively.

The objective of this study was to determine the effect of self-relaxing yogic eye exercises followed by the ergonomic advice on eye fatigue in school-aged children attending online classes. The study was carried out on 44 school-aged children attending online classes. They were asked to follow the eye exercises along with ergonomic advice for 6 days per week (twice a day) as a 4 weeks protocol. After the eye exercises, we asked them to practice the Shavasana for 20 minutes to relax their eyes. Eyesight is one of the most important senses. So it is important to protect our eyes which will reduce the odds of blindness and vision loss.

Eye fatigue was significantly reduced in the post-exercise session followed by the ergonomic advice as compared to the pre-exercise session in school-aged children attending online classes.

Consequently, this study focuses on how self- relaxing yogic eye exercises followed by the ergonomic advice can reduce eye fatigue.

\section{CONCLUSION}

The study was carried out to find the effect of self-relaxing yogic eye exercises followed by the ergonomic advice on eye fatigue in school-aged children attending online classes in COVID-19. The data was assessed and a significant decline was found in the eye fatigue in them.

\section{LIMITATIONS OF THE STUDY}

- The study is limited to a small sample size.

- Inadequate time for the study.

- As this study was conducted through an online session, we can not exactly predict whether the result and information given by subjects are precise

\section{SUGGESTIONS AND RECOMMENDATIONS}

- This project can be further taken up for the studies so that we can properly assess the subjects and find out the actual effect of self- relaxing yogic eye exercises followed by the ergonomic advice on eye fatigue in school-aged children attending online classes.

- Adequate time should be given to screening the target population.

Acknowledgement: Authors acknowledge the immense help received from the scholars whose articles are cited and included in references of this manuscript. The authors are also grateful to authors / editors / publishers of all those articles, journals and books from where the literature for this article has been reviewed and discussed.

\section{Conflict of interest: None}

\section{Source of funding: Nil}

\section{REFERENCES}

1. Telles S, Naveen KV, Dash M, et al.: Effect of yoga on self-rated visual discomfort in computer users. Head Face Med, 2006, 2: 46.

2. Rideout V., Foehr U., and. Roberts, D, Generation M2: Media in the lives of 8 to 18-year-olds. California, USA: A Kaiser Family Foundation Study. (\#8010). Retrieved from www.kff.org. 2010.

3. Straker L, Pollock C., 2005. Optimizing the interaction of children with information and communication technologies. Ergonomics, 48, 506-521.

4. Roberts D., Foehr U., and Rideout, V., Generation M: Media in the Lives of 8 - 18-Year-Olds. California, USA: Kaiser Family Foundation. Retrieved from www.kff.org. September 12, 2008.

5. Kappos A., The impact of electronic media on mental and somatic children's health. IJHEH, 2007; 210 : 555-562.

6. Straker, L., Maslen B., Burgess-Limerick R., Johnson P., and Dennerlein J., Evidence-based guidelines for the wise use of computers by children: Physical development guidelines. Ergonomics, 2010; 53: 458-477.

7. Australian Bureau of Statistics (ABS). Household use of information technology, 2008 - 2009. Canberra. http://www.abs.gov. au/Ausstats/abs@.nsf/0/A4A719717D5B359BCA2575220013 CF6B?OpenDocument. Accessed November 10, 2010.

8. US Census Bureau (UCB). The 2008 Statistical Abstract, Information and Communications. http://www.census.gov/compendia/statab/2008/cats/information_communications.html, 2008.

9. Olds T., Ridley K., and Dollman J., Screenieboppers and extreme screenies: the place of screen time in the time budgets of 10-13-year-old Australian children. Australian and New Zealand Journal of Public Health, 2006; 30: 137-142. 
10. Orleans M., and Laney M., Children's computer use in the home: Isolation or Sociation? Social Science Computer Review, 2000;18:56-72.

11. Roberts D., Foehr U., and Rideout V., Generation M: Media in the Lives of 8 - 18-Year-Olds. California, USA: Kaiser Family Foundation. Retrieved from www.kff.org. September 12, 2008, 2005.

12. Kent N. and Facer K., Different worlds? A comparison of young people's home and school ICT use. Journal of Computer Assisted Learning, 2004;20: 440-455.

13. Borzekowski D., and Robinson T., The remote, the mouse, and the no. 2 pencils. Archives of Pediatrics and Adolescent Medicine, 159 (2005), 607-613.

14. Yuji H. Computer games and information - processing skills. Perceptual and Motor Skills 1996;83: 643-647.

15. Hamer M, E Stamatakis., and Mishra G., Psychological distress, television viewing, and physical activity in children. Paediatrics, 2009; 123: 1263-1268.

16. Harris C., and Straker L., Survey of the physical ergonomics issues associated with school children's use of laptop computers. International Journal of Industrial Ergonomics,2000; 26: 337346.
17. Dworak M., Schierl, T. Bruns T. and Struder H.K., Impact of singular excessive computer game and television exposure on sleep patterns and memory performance of school-aged children. Pediatrics, 2007;120 (5): 978-985.

18. Yang CY, Sato T, Yamawaki N, et al.: Prevalence and risk factors of problematic Internet use: a cross-national comparison of Japanese and Chinese university students. Transcult Psychiatry, 2013, 50: 263-279.

19. Satyanada SS: Asana Pranayama Mudra Bandha. In: Yoga Exercises for the Eyes. India: Bihar Yoga Bharati Yoga Publication Trust, 2006; 74-84.

20. Yoo WG: Comparison of orbicularis oculi muscle activity during computer work with single and dual monitors. J Phys Ther Sci, 2014, 26: 1807-1808.

21. Hedstrom J: A note on eye movements and relaxation. J Behav Ther Exp Psychiatry, 1991, 22: 37-38.

22. Beets MW, Mitchell E: Effects of yoga on stress, depression, and health-related quality of life in a nonclinical, bi-ethnic sample of adolescents: a pilot study. Hisp Health Care Int, 2010, 8: 47-53.

23. Telles $S$, Nagarathna R, Nagendra HR: Improvement in visual perception following yoga training. J Indian Psychol, 1995, 13: 30-32. 